\title{
BMJ Open Healthcare utilisation and expenditure patterns for cardio-metabolic diseases in South Asian cities: the CARRS Study
}

Priti Gupta (1) , ${ }^{1}$ Kalpana Singh, ${ }^{1}$ Roopa Shivashankar, ${ }^{1}$ Kavita Singh, ${ }^{2}$ Ajay Vamadevan, ${ }^{1}$ V Mohan, ${ }^{3}$ Muhammad Masood Kadir, ${ }^{4}$ Nikhil Tandon, ${ }^{5}$ K M Narayan, ${ }^{6}$ Dorairaj Prabhakaran, ${ }^{1,2}$ Mohammed K Ali ${ }^{7}$

To cite: Gupta P, Singh K, Shivashankar R, et al. Healthcare utilisation and expenditure patterns for cardio-metabolic diseases in South Asian cities: the CARRS Study. BMJ Open 2020;10:e036317. doi:10.1136/ bmjopen-2019-036317

- Prepublication history for this paper is available online. To view these files, please visit the journal online (http://dx.doi. org/10.1136/bmjopen-2019036317).

Received 12 December 2019 Revised 20 July 2020 Accepted 07 August 2020
Check for updates

(C) Author(s) (or their employer(s)) 2020. Re-use permitted under CC BY-NC. No commercial re-use. See rights and permissions. Published by BMJ.

For numbered affiliations see end of article.

Correspondence to

Dr Priti Gupta;

priti2317@gmail.com

\section{ABSTRACT}

Objective To estimate average annual expenditures per person, total economic burden and distress health financing associated with the treatment of five cardiometabolic diseases (CMDs-hypertension, diabetes, heart disease (angina, myocardial infarction and heart failure), stroke and chronic kidney disease) in three metropolitan cities in South Asia.

Design Cross-sectional surveys.

Setting We analysed community-based baseline data from the Centre for cArdio-metabolic Risk Reduction in South Asia (CARRS) Study collected in 2010-2011 representing Chennai and New Delhi (India), and Karachi (Pakistan).

Participants We used data from non-pregnant adults ( $\geq 20$ years) from the aforementioned cities that responded to a cost-of-illness questionnaire. We estimated health utilisation and expenditures among those reporting taking treatment(s) for the aforementioned CMDs in the last 1 year. We converted all costs to International Dollars (Int\$ 2011) and inflated to 2018 values. The annual costs per person were stratified by city, sociodemographic characteristics, contributor of costs and financing methods. The total economic burden of CMDs for each city was projected using age-standardised prevalence and per-person costs of diseases reported in CARRS, applying these to population data from the most recent census. We also calculated distress financing (DF) as having to borrow or sell assets to pay for CMD treatment and identified sociodemographic groups at most risk of DF using multiple regression.

Results Of 16287 CARRS participants, 2883 (17.7\%) reported receiving treatment for CMDs. The total annual expenditures reported per patient for CMDs ranged from Int\$358 to Int\$2425. Medications constituted 46\% of total direct expenditures and out-of-pocket (OOP) expenditures accounted for nearly $80 \%$ of financing these health expenditures. Total economic burdens of CMDs were Int\$0.42 billion, Int\$3.4 billion and Int\$1.4 billion in Chennai, New Delhi and Karachi, respectively. Overall, $36.1 \%$ experienced $\mathrm{DF}$, and women $(\mathrm{OR}=4.4)$, unemployed $(\mathrm{OR}=10.7)$ and uninsured $(\mathrm{OR}=8.1)$ adults experienced higher odds of DF.

Conclusion CMDs are associated with large economic burdens in South Asia. Due to most payments coming from OOP expenditures and limited insurance, the odds of DF are high.

\section{Strengths and limitations of this study}

- First large community-based study from South Asia with primary data collected for cost-of-illness estimation for cardio-metabolic diseases.

- Calculation of economic burdens for entire cities using prevalence and economic survey data from the same population which is an ideal approach to calculate cost of illness and loss of productivity for a city.

- First estimates of distress health financing from a community-based study.

- The health service utilisation and expenditure data were self-reported and are subject to reporting biases.

- Utilisation and cost of treatments were collected for the previous year, therefore it is subjected to recall bias.

\section{BACKGROUND}

Non-communicable disease (NCD) burdens are increasing worldwide, especially in low/ middle-income countries (LMICs). Cardiovascular diseases (CVD) and diabetes mellitus (DM) account for nearly $50 \%$ of NCD deaths. ${ }^{1}$ Due to economic growth and development in the past two decades in South Asian countries, the burden of NCDs is increasing at nearly twice the rate in comparison to the rest of the world. ${ }^{2}$ For instance, between 1990 and 2010, disability-adjusted life years from ischaemic heart disease and DM were estimated to have increased by $73 \%$ and $104 \%$ in South Asia, respectively, compared with $30 \%$ and $70 \%$ in other parts of the world. ${ }^{3}$

Growing NCDs is a challenge for the health systems in South Asia that still contend with infectious diseases and hence face a 'double burden' of disease. ${ }^{4}$ Health systems in this region are not yet equipped and engineered to conduct early diagnosis and management of chronic diseases like high blood pressure, glucose or cholesterol. This requires robust primary care facilities with specific screening 
programmes and access to health education, laboratory facilities, and a consistent and reliable availability of essential medicines. ${ }^{4-6}$

Due to lack of adequate publicly funded health facilities and limited health insurance coverage, most health expenditures are out-of-pocket (OOP) causing substantial economic impacts for individuals, households and communities. ${ }^{7-11}$ In this context, a comprehensive evaluation of the economic burden of cardio-metabolic diseases (CMDs) is valuable so that the financial burden of these diseases is adequately addressed in the universal health coverage reforms in these countries. ${ }^{12} \mathrm{Few}$ published reports had evaluated the economic burden of CMDs. ${ }^{710}$ However, existing studies have suffered from methodological inconsistencies, small sample sizes and limited availability of highly precise disease prevalence estimates. To address gaps in understanding of average per-person annual spending on CMDs and their sources of financing, we analysed costs of care for five CMDs namely: hypertension (HTN, DM, heart disease (HD), stroke (ST) and chronic kidney diseases (CKD) from a large communitybased study in India and Pakistan.

\section{METHODS}

\section{Data collection}

We used data from the baseline survey of the Centre for cArdiometabolic Risk Reduction in South Asia (CARRS). The details of the CARRS Study are published elsewhere. ${ }^{13} 14$ In short, CARRS recruited 16287 adults aged $\geq 20$ years using multistage cluster random sampling from urban cities of Chennai and New Delhi (India) and Karachi (Pakistan) over 2010-2011. Trained interviewers collected data through household interviews in local languages using standardised questionnaires and obtained anthropometric and blood pressure measurements. Fasting blood and urine samples were collected either at home (Karachi) or at local camps (New Delhi and Chennai). The cost data questions were based on the Initiative for Cardiovascular Health Research in the developing countries macroeconomic study. ${ }^{15}$

We piloted the questionnaires before the survey and interviewer debriefing methods were used to assess any difficulty or variation in understanding of the items in the questions; the wording of the questionnaires was then modified accordingly. Participants were asked if they received either outpatient (OP) or inpatient (IP) hospitalisation treatment for one or more CMDs-HTN, coronary heart disease (CHD: angina, myocardial infarction or heart failure), ST, DM or its complications, and CKD in the previous 12 months. If affirmative for OP treatment, participants were asked the number of visits and medical expenditures for each of the following categories: consultation fees, laboratory or radiological tests, medications, physical therapy and home nurse care for each visit in the past 12 months. If the participant was hospitalised for the above-mentioned CMDs, then they were asked about the number of times hospitalised, length of hospital stay(s), and associated costs of hospital stays, costs of any surgical or other procedures, lab tests and medications for each hospitalisation in the past 12 months.

Additionally, for each OP visit and/or hospitalisation, we collected data on direct non-medical expenditures such as expenses on travel to and from clinic/hospital, time spent waiting at the clinic, consultation time (for $\mathrm{OP})$, and the number of days spent by the respondent and their caregivers in the hospital (for IP).

We also collected information on the type of healthcare setting-government, private, charity or other. Further, participants were asked about the source(s) of financing used (own savings, payment by family members, insurance, loans (relatives/friends or banks/other lenders) and sale of assets) and the proportion of healthcare expenditures that were derived from each of these sources.

\section{Variable definitions \\ Covariates}

We used participants' reported age, gender, marital status, education, employment status and occupation as covariates. Based on participants' responses, we categorised education level (up to primary schooling, high school or secondary, college graduation and above); wealth; employment status (employed, homemaker, student, unemployed, retired) and occupation (not working outside the home, unskilled/semiskilled, trained/skilled, white-collar). For calculating wealth, we used an index of household amenities and assets. We used principal components analysis methods ${ }^{14}$ and categorised wealth in tertiles. Details of these methods are provided in a previous publication. ${ }^{13}$

\section{Per-patient expenditures}

We used cost-of-illness methods to calculate the economic burdens of CMDs. To provide comprehensive estimates of health expenditures, we included both direct medical and direct non-medical expenditures of each disease annually. ${ }^{16}$ We derived direct medical expenditures for each CMD by adding the expenditures reported by participants for medications, lab investigations, OP consultations and hospitalisations. We calculated direct non-medical expenditures by aggregating participant-reported transportation costs to and from the clinic/hospital and the costs of boarding and lodging of attendants (only in the case of hospitalisation). We estimated total direct expenditures by adding direct medical and non-medical expenditures. ${ }^{17}$ Here, we report annual per-patient expenditures for individual CMDs-DM, HTN, CHD, ST and CKDand combinations of these: (1) DM+HTN and (2) HTN/ $\mathrm{DM}+\mathrm{HD} / \mathrm{CKD} / \mathrm{ST}$ (ie, hypertension or diabetes with any of heart disease, chronic kidney disease, and/or stroke).

Indirect costs (ie, productivity loss) were estimated on the basis of the number of days lost for consultations, hospitalisations or treatments ${ }^{17}$ reported by participants of economically productive age (20-64 years).${ }^{18}$ We used the time spent in the clinic (waiting/consultation or for investigations) and the number of days hospitalised 


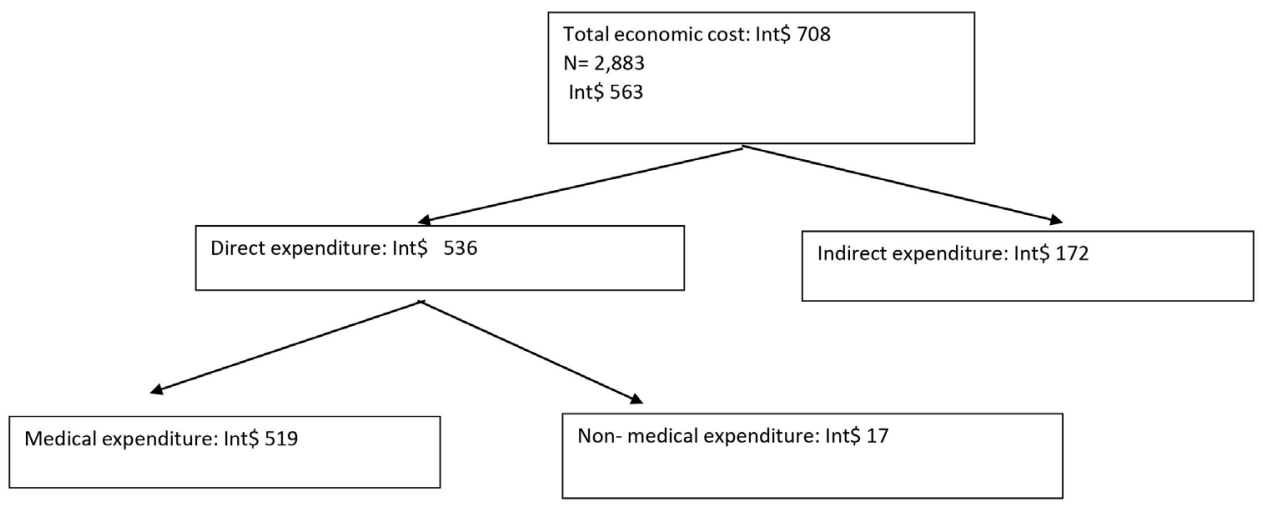

Figure 1 Annual mean cost per person of cardio-metabolic diseases in three cities in South Asia.

for this calculation. We considered less than 4 hours as half a day loss and 4 hours or more as loss of an entire day (considering an average of 8 working hours a day as the standard). Since individual-level income data were not available to estimate productivity losses, we used minimum wage to compute indirect costs due to illness. The number of days lost for each participant was then multiplied by the minimum wage for that city in the year 2017-2018. Minimum wages used for Chennai, New Delhi and Karachi were 352 Indian rupees (Int\$23.3), ${ }^{19}$ 534 Indian rupees $(\operatorname{Int} \$ 35.3)^{20}$ and 500 Pakistani rupees $(\operatorname{Int} \$ 20.5)$ per day, ${ }^{21}$ respectively.

The total costs of diseases were calculated by adding direct and indirect costs (figure 1). We extrapolated these data to estimate the total economic burden for each city. We estimated the portion of expenditures that were OOP by subtracting the amounts paid by insurance from total direct expenditures. ${ }^{22}$

\section{Distress financing}

Participants were considered to be incurring distress financing (DF) if the participants reported that their source of financing treatment of CMDs included borrowing money from relatives or friends, taking loans from banks or other lenders, or selling assets. ${ }^{23}$

We converted all reported direct and indirect expenditures in Indian rupees and Pakistani rupees to 2011 Purchasing Power Parity-adjusted International Dollars (Int\$), the year for which data were collected and presented in this paper. ${ }^{24}$ We inflated these costs to the 2018 US\$ value. 2526

\section{Data analysis}

Sampling weights were used to account for the complex, multistage design of the CARRS surveys to ensure that the findings are representative of each city. Demographic and socioeconomic profiles were described as percentages (with $95 \%$ CIs), from each city and cumulatively.

For all medical expenditures, each unit of resource use was multiplied with their frequency in the last 1 year, to calculate the annual cost for that category. The expenditure on OP and IP treatments were presented as means (SE). Given that cost data were unlikely to be normally distributed, the bootstrap method was used to calculate
SEs and $95 \%$ CIs were estimated for average costs. ${ }^{27} \mathrm{We}$ also estimated individual expenditures across different age groups, socioeconomic groups, educational, occupation groups and cities.

We estimated what proportion of health expenditures were financed through different means: OOP expenditures, insurance and others. We then calculated the proportion of adults that needed to avail of DF to cover health expenditures. Then, we used univariate and multivariate logistic regression to assess which social, demographic and clinical factors were associated with higher probability of DF. The multivariate models were constructed using those variables that were significant $(\mathrm{p}<0.1)$ in the univariate models using a forward stepwise approach.

To calculate the economic burden for each city, we calculated the size of the at-risk population (ie, age $\geq 20$ years) from the age-specific distributions of the populations of New Delhi, Chennai and Karachi using the latest available census data. ${ }^{28}{ }^{29}$ For diagnosed CMDs, we estimated prevalence in each city using self-reported physician-diagnosed DM, HTN, CHD, ST and CKD from the CARRS survey. For DM and HTN, we also estimated the total prevalence (both diagnosed and undiagnosed) by including participants who did not report DM or HTN, but had measured blood pressure $\geq 140 / 90 \mathrm{~mm} \mathrm{Hg}$ (for HTN) and measured fasting plasma glucose $\geq 126 \mathrm{mg} / \mathrm{dL}$ or glycated haemoglobin HbAlc $\geq 6.5 \%$ (for DM). The size of the affected population was calculated by multiplying the age-standardised prevalence of disease from the CARRS survey with the population at risk in each city. Prevalence was standardised to the 2010 world population, to compare these estimates with other global cities that have different population structures. Then, the per-patient average annual cost for each disease was applied to the size of the affected population, to get the total estimated cost of the disease for the city using the following equation:

Cost projections for city=size of the affected population $\times$ nnual per-person expenditures for the disease where the size of affected population=age-standardised prevalence for the disease (standardised to world population 2010) $\times$ size of the population aged 20 years and above/100. 
STATA V.12.1 (STATA Corporation, College Station, Texas, USA) was used for statistical analysis.

\section{Patient and public involvement}

It was not appropriate or possible to involve patients or the public in the design, or conduct, or reporting, or dissemination of our research.

\section{Role of the funding source}

The funding source had no role in the design of this study and will not have any role during its execution, analyses, interpretation of the data or decision to submit results.

\section{RESULTS}

Out of the 16287 recruited participants, 3707 had selfreported CMDs (HTN, CHD, ST, DM and/or CKD). However, only $2883(78 \%)$ had received treatment in the prior year. Nearly $14 \%$ of patients with CHD, $63 \%$ of patients with ST and $45 \%$ of patients with CKD reported not receiving treatment in the last 12 months (see online supplemental table S1).

Table 1 presents demographic, socioeconomic and CVD risk factor characteristics of the 2883 respondents who were treated for CMDs in the prior year. The mean age of participants was $51.4(\mathrm{SD}=11.4)$ years, and women

Table 1 Demographic and socioeconomic characteristics of participants (who provided cost data) across all cities (total $\mathrm{N}=2883$ )

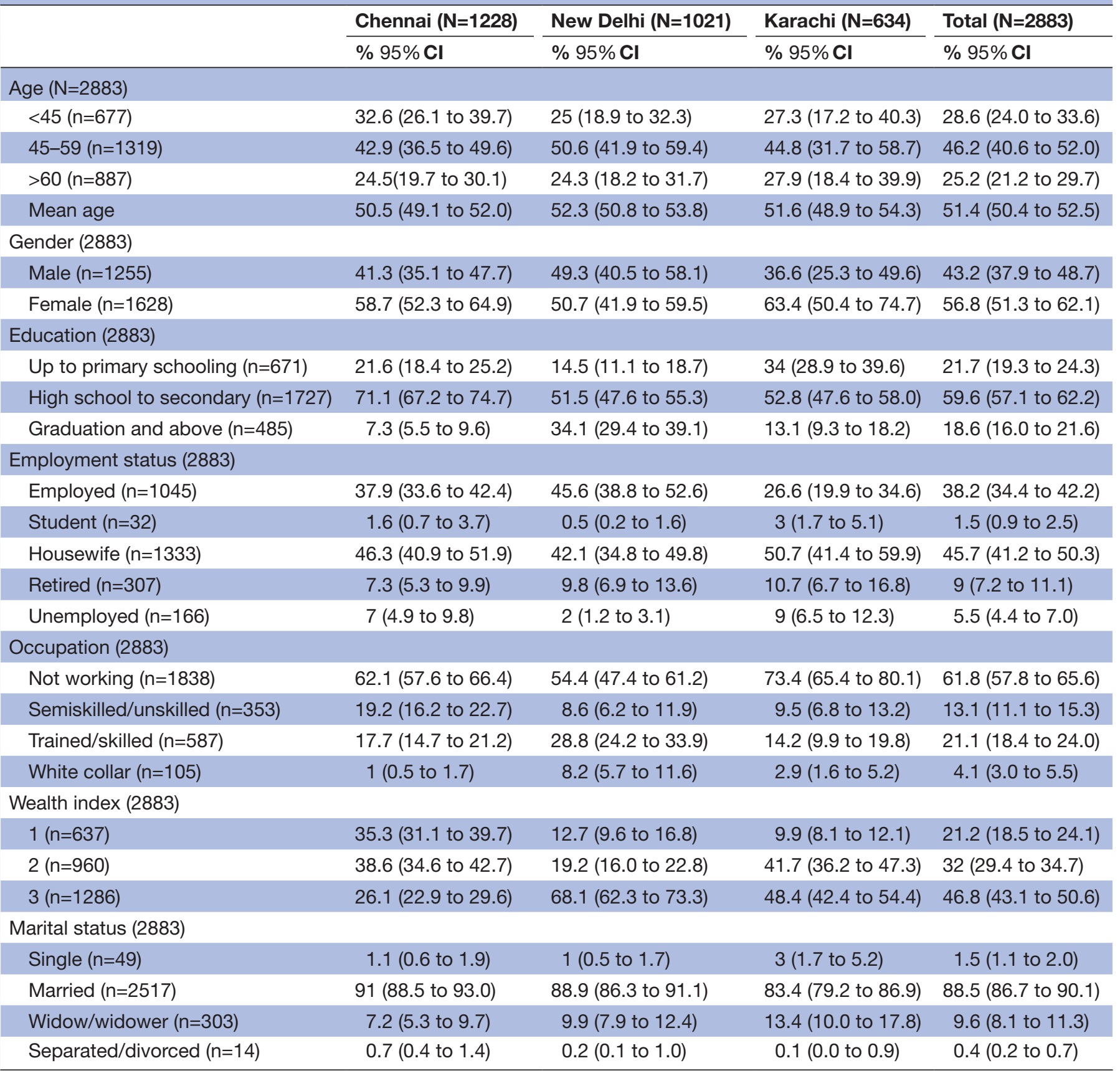


constituted $56.8 \%$. Most sociodemographic characteristics were distributed similarly among all the cities except wealth and education. New Delhi had the larger proportions of participants in the highest wealth tertile $(68 \%)$ and graduate-level education $(34 \%)$, compared with $28.6 \%$ and $48.4 \%$ in Chennai, and $7.3 \%$ and $13.1 \%$ in Karachi, respectively.

For both OP and IP care, more than $60 \%$ of participants reported using private health facilities. Across all three cities, the primary source of financing was their own household savings (52.5\% in OP and $47.3 \%$ in IP).
Overall, insurance covered $3.3 \%$ of OP and $14.2 \%$ of IP services used. Chennai had the lowest insurance coverage (OP: $2.1 \%$, IP: $8 \%$ ) and highest government health facility utilisation (OP: 28.1\%, IP: 22.2\%) among all three cities' residents. The average time spent in $\mathrm{OP}$ visits and time to each health facility was 60 and $28 \mathrm{~min}$, respectively. The average number of OP visits for all CMDs ranged from 5 to 11 per year, with the lower end of visits observed for patients with DM and the higher end of visits observed for patients with CKD (table 2).

Table 2 Type of health facility and source of financing for healthcare

\begin{tabular}{|c|c|c|c|c|}
\hline & Chennai & New Delhi & Karachi & Total \\
\hline \multicolumn{5}{|l|}{ Type of health facility (OP care) (2852) } \\
\hline Government $(\mathrm{n}=786)$ & $36.5(32.7,40.5)$ & $26.1(22.3,30.4)$ & $10.1(7.9,13.0)$ & $26.8(24.4,29.3)$ \\
\hline Private $(n=2021)$ & $62.4(58.4,66.3)$ & $72.3(68.1,76.2)$ & $87.5(84.6,90.0)$ & $71.7(69.2,74.0)$ \\
\hline Charity $(n=45)$ & $1.1(0.5,2.1)$ & $1.5(0.8,2.7)$ & $2.3(1.4,3.7)$ & $1.5(1.1,2.1)$ \\
\hline \multicolumn{5}{|l|}{ Type of health facility (IP care) $(n=114)$} \\
\hline Government $(n=40)$ & $48.7(32.4,65.4)$ & $33.2(17.7,53.4)$ & $27.1(16.2,41.8)$ & $37.2(28.6,46.8)$ \\
\hline Private $(n=71)$ & $48.7(32.5,65.2)$ & $66.8(46.6,82.3)$ & $67.9(53.2,79.8)$ & $60.1(50.7,68.9)$ \\
\hline Charity $(n=3)$ & $2.6(0.3,16.8)$ & 0 & $5(1.2,17.9)$ & $2.6(0.8,8.0)$ \\
\hline $\begin{array}{l}\text { Time spent in OP per visit (min) }(\mathrm{N}=2875) \text { (mean } \\
\text { (SD)) }\end{array}$ & $68.6(56.4)$ & $53.5(63.7)$ & $51.2(55.8)$ & $59.1(59.5)$ \\
\hline $\begin{array}{l}\text { Time spent to reach hospital/clinic per visit (min) } \\
(\mathrm{N}=2875)(\text { mean }(\mathrm{SD}))\end{array}$ & $29.6(21.1)$ & $28.9(26.2)$ & $23.8(18.8)$ & $28(23)$ \\
\hline Number of OP visit $(\mathrm{N}=2875)$ (mean (SD)) & $5.2(5)$ & $7.1(9.7)$ & $6.4(8.1)$ & $6.2(7.9)$ \\
\hline HTN & $5.2(4.9)$ & $7.2(10.2)$ & $6.7(9.4)$ & $6.4(8.6)$ \\
\hline DM & $4.5(4.3)$ & $5.6(6.1)$ & $6.5(8.8)$ & $5.2(5.9)$ \\
\hline HD & $6.5(6.5)$ & $6.3(8.5)$ & $3.8(4.6)$ & $5.6(7)$ \\
\hline CKD & $2.6(1.3)$ & $54.4^{\star}(43.6)$ & $4.8(6.5)$ & $11(23.7)$ \\
\hline ST & $7.2(6)$ & $6.9(6.4)$ & $10.7(1)$ & $8.1(5.5)$ \\
\hline HTN+DM & $5.6(5)$ & $7.8(8)$ & $6.4(5.7)$ & $6.5(6.5)$ \\
\hline $\mathrm{HTN} / \mathrm{DM}+\mathrm{HD} / \mathrm{CKD} / \mathrm{ST}$ & $6.5(5.7)$ & $9.7(15.3)$ & $6.6(5.8)$ & $7.6(10)$ \\
\hline \multicolumn{5}{|l|}{ OP visit financing source† $(\mathrm{N}=2876)$} \\
\hline Own saving $(\mathrm{N}=1511)$ & $44.8(41.0,48.6)$ & $61.3(55.5,66.8)$ & $51.8(46.8,56.7)$ & $52.5(49.4,55.6)$ \\
\hline Family members paid $(\mathrm{N}=1010)$ & $28.1(24.3,32.2)$ & $37(31.5,42.8)$ & $45.5(39.7,51.4)$ & $35.3(32.4,38.3)$ \\
\hline Insurance $(\mathrm{N}=94)$ & $2.1(1.2,3.8)$ & $4.5(3.3,6.3)$ & $3.2(2.0,5.0)$ & $3.3(2.6,4.2)$ \\
\hline $\begin{array}{l}\text { Other (government/charity hospital/borrowed from } \\
\text { friend or bank) }(\mathrm{N}=366)\end{array}$ & $28.1(24.7,31.8)$ & $2.4(1.5,4.1)$ & $0.8(0.3,1.8)$ & $12.4(10.7,14.4)$ \\
\hline \multicolumn{5}{|l|}{ IP care financing source $\dagger(\mathrm{N}=95)$} \\
\hline Own saving $(\mathrm{N}=44)$ & $50.4(30.9,69.8)$ & $51.6(28.8,73.8)$ & $39.6(21.5,61.1)$ & $47.3(35.0,59.9)$ \\
\hline Family members paid $(\mathrm{N}=35)$ & $32.7(16.8,53.9)$ & $19.4(7.4,41.8)$ & $45.9(30.9,61.7)$ & $33.5(23.8,44.9)$ \\
\hline Borrowed from friend, relatives or bank $(\mathrm{N}=4)$ & $1.9(0.4,9.1)$ & $9.3(1.3,44.0)$ & $4(0.5,24.5)$ & $4.5(1.3,14.2)$ \\
\hline Insurance $(\mathrm{N}=13)$ & $8(2.4,23.6)$ & $19.8(7.6,42.3)$ & $18.2(8.2,35.5)$ & $14.2(7.7,24.8)$ \\
\hline Other (government/charity hospital) $(\mathrm{N}=8)$ & $22.2(9.3,44.3)$ & 0 & $3.2(0.4,20.2)$ & $10.5(4.7,21.7)$ \\
\hline Distress health financing $(\mathrm{N}=2866)$ & $29.3(25.5,33.4)$ & $37.2(31.7,43)$ & $46.4(40.9,52.1)$ & $36.1(33.3,39)$ \\
\hline
\end{tabular}

${ }^{*}$ Higher than other cities as one participant had 96 visits in last 1 year.

†Multiple responses.

CKD, chronic kidney disease; DM, diabetes mellitus; HD, heart disease; HTN, hypertension; IP, inpatient; OP, outpatient; ST, stroke. 


\section{Per-patient expenditure}

Total annual mean health expenditures for all CMDs in Chennai, New Delhi, Karachi, and the average for all cities were Int $\$ 467$, Int $\$ 979$, Int $\$ 684$ and Int $\$ 708$, respectively. The total average annual direct and indirect expenditure per person were Int $\$ 536$ and Int $\$ 171$, respectively (figure 1 ). Overall, mean annual costs per patient for HTN, DM, CHD, $\mathrm{ST}, \mathrm{CKD}, \mathrm{HT}+\mathrm{DM}$, and $\mathrm{HT} / \mathrm{DM}+\mathrm{CHD} / \mathrm{ST} / \mathrm{CKD}$ were Int $\$ 358$, Int $\$ 469$, Int $\$ 1831$, Int $\$ 2425$, Int $\$ 870$, Int $\$ 713$ and Int $\$ 2342$, respectively. In all cities, average total OP expenditures were higher than IP expenditures. Medications constituted the majority (46\%) of direct expenditures (see online supplemental table $\mathrm{S} 2$ ).

Total direct and OOP expenditures were highest in the age group 45-60years. People with higher education had more total direct and OOP expenditures. However, as a percentage of OOP expenses, people in white-collar jobs and of higher wealth index had the lowest expenditures relative to their wealth/income (table 3 ).

\section{Distress financing}

DF for Chennai, New Delhi and Karachi were reported by $29.2 \%, 37.2 \%$ and $46.4 \%$, respectively, of participants with CMDs (table 2). After adjustment for sociodemographic variables, city and insurance, and female gender, unemployed individuals and people without insurance were more likely to incur DF. Wealth and education were not associated with DF (table 4).

Total economic burden (projections at population level)

Total economic burdens of self-reported CMDs were Int $\$ 0.4$ billion, Int $\$ 3.4$ billion and Int $\$ 1.4$ billion in

Table 3 Sociodemographic correlates of direct and out-of-pocket (OOP) health expenditure

\begin{tabular}{|c|c|c|c|}
\hline Variable & $\begin{array}{l}\text { Total direct expenditure } \\
\text { cost (in Int\$), mean (SE) }\end{array}$ & $\begin{array}{l}\text { OOP expenditure (in Int\$), } \\
\text { mean (SE) }\end{array}$ & $\begin{array}{l}\text { OOP/total direct } \\
\text { expenditure (\%) }\end{array}$ \\
\hline \multicolumn{4}{|l|}{ Age (years) } \\
\hline$<45(\mathrm{n}=677)$ & $370(31.6)$ & $312(21.9)$ & 84.4 \\
\hline $45-59(n=1319)$ & $606(70.9)$ & $447(53.8)$ & 73.8 \\
\hline$>60(\mathrm{n}=887)$ & $596(82.6)$ & $453(42.2)$ & 76.1 \\
\hline \multicolumn{4}{|l|}{ Gender } \\
\hline Male $(n=1252)$ & $610(75.8)$ & $467(50.0)$ & 76.6 \\
\hline Female $(n=1628)$ & $480(45.7)$ & $367(27.1)$ & 76.5 \\
\hline \multicolumn{4}{|l|}{ Education } \\
\hline Up to primary schooling $(n=671)$ & $479(99.8)$ & $299(21.0)$ & 62.4 \\
\hline High school to secondary $(n=1727)$ & $501(40.0)$ & 409 (32.9) & 81.7 \\
\hline Graduation and above $(n=485)$ & $716(117.9)$ & $545(71.1)$ & 76.1 \\
\hline \multicolumn{4}{|l|}{ Employment status } \\
\hline Employed $(n=1045)$ & 516 (62.) & $372(36.8)$ & 72.1 \\
\hline Student $(n=32)$ & $751(297.4)$ & 419 (139.1) & 55.8 \\
\hline Housewife $(n=1333)$ & $462(38.7)$ & $400(32.3)$ & 86.8 \\
\hline Retired $(n=307)$ & $937(199.8)$ & $589(88.1)$ & 62.9 \\
\hline Unemployed $(n=166)$ & $580(178.3)$ & $460(164.2)$ & 79.4 \\
\hline \multicolumn{4}{|l|}{ Occupation } \\
\hline Not working $(n=1838)$ & $548(46.5)$ & $434(30.7)$ & $548(46.5)$ \\
\hline Semiskilled/unskilled $(n=353)$ & $306(36.3)$ & $268(37.2)$ & $306(36.3)$ \\
\hline Trained/skilled $(n=587)$ & $587(85.1)$ & $421(52.3)$ & $587(85.1)$ \\
\hline White collar ( $n=105)$ & $824(412.7)$ & 456 (85.) & $824(412.7)$ \\
\hline \multicolumn{4}{|l|}{ Wealth index } \\
\hline $1(n=637)$ & $278(46.4)$ & $227(32.7)$ & 81.7 \\
\hline $2(n=960)$ & $402(34.7)$ & $312(22.9)$ & 77.7 \\
\hline $3(n=1286)$ & 744 (71.2) & $560(51.9)$ & 75.2 \\
\hline \multicolumn{4}{|l|}{ City } \\
\hline Chennai $(n=1228)$ & 335 (30.4) & $292(24.4)$ & 87.2 \\
\hline New Delhi $(n=1021)$ & $744(71.4)$ & $564(57.6)$ & 75.9 \\
\hline Karachi $(n=634)$ & $550(84.9)$ & $366(38.8)$ & 66.5 \\
\hline
\end{tabular}


Table 4 Univariate and multivariate logistic regression for distress financing

\begin{tabular}{|c|c|c|c|c|}
\hline \multirow{3}{*}{ Age (years) (2883) } & \multirow{2}{*}{$\begin{array}{l}\text { Univariate analysis } \\
\text { OR }(95 \% \mathrm{Cl})\end{array}$} & \multirow[b]{2}{*}{ P value* } & \multirow{2}{*}{$\begin{array}{l}\text { Multivariate analysis } \\
\text { OR }(95 \% \mathrm{Cl})\end{array}$} & \multirow[b]{2}{*}{$P$ value } \\
\hline & & & & \\
\hline & & & & \\
\hline $45-59(n=1319)$ & $1.1(0.8-1.5)$ & 0.5 & $1.1(0.8-1.4)$ & 0.33 \\
\hline$>60(\mathrm{n}=887)$ & $1.5(1.1-2.1)$ & 0.006 & $1.3(0.9-1.9)$ & 0.21 \\
\hline Female $(n=1621)$ & $8.2(6.4-10.5)$ & $<0.001$ & $4.4(2.8-7.1)$ & $<0.001$ \\
\hline \multicolumn{5}{|l|}{ Education (2870) } \\
\hline Up to primary schooling $(n=671)$ & $3.1(2.2-4.4)$ & $<0.001$ & $1.3(0.8-1.9)$ & 0.14 \\
\hline High school to secondary $(n=1715)$ & $1.7(1.3-2.4)$ & 0.001 & $1.2(0.9-1.7)$ & 0.21 \\
\hline Student (32) & $10.3(4.6-23.2)$ & $<0.001$ & $8.9(2.6-30.1)$ & $<0.001$ \\
\hline Housewife (1327) & $11.9(8.8-16.2)$ & $<0.001$ & $6.6(2.6-17.0)$ & $<0.001$ \\
\hline Retired (302) & $3.1(2.2-4.6)$ & $<0.001$ & $5.5(2.1-14)$ & $<0.001$ \\
\hline Unemployed (167) & $8.2(5.1-13.2)$ & $<0.001$ & $10.7(3.7-30.8)$ & $<0.001$ \\
\hline \multicolumn{5}{|l|}{ Occupation among employed (2866) } \\
\hline Not working $(n=1828)$ & $15.3(6.6-35)$ & $<0.001$ & \multicolumn{2}{|c|}{ Omitted because of collinearity } \\
\hline Semiskilled/unskilled ( $n=351)$ & $2.1(0.9-5.2)$ & 0.1 & $2.1(0.8-6)$ & 0.10 \\
\hline Trained/skilled $(n=582)$ & $1.4(0.6-3.4)$ & 0.4 & $1.5(0.6-3.6)$ & 0.50 \\
\hline White collar $(n=105)$ & Ref & & Ref & \\
\hline Married $(n=2503)$ & $1.9(0.9-3.9)$ & 0.08 & $1.2(0.8-1.7)$ & 0.38 \\
\hline Widow/widower $(n=300)$ & $4.2(1.9-9)$ & $<0.001$ & $1.8(0.9-3.8)$ & 0.12 \\
\hline Separated/divorced $(n=14)$ & $5.9(1.5-23.5)$ & 0.012 & $1.6(0.7-3.4)$ & 0.28 \\
\hline \multicolumn{5}{|l|}{ City (2866) } \\
\hline Chennai $(n=1217)$ & Ref & & Ref & \\
\hline New Delhi $(n=1018)$ & $1.4(1.04-2)$ & $<0.001$ & $2.4(1.0-20.7)$ & $<0.001$ \\
\hline Karachi $(n=631)$ & $2.1(1.6-2.8)$ & $<0.001$ & $2.2(1.7-2.7)$ & $<0.001$ \\
\hline \multicolumn{5}{|l|}{ Insurance (2865) } \\
\hline Yes (100) & Ref & & Ref & \\
\hline No (2765) & $7.2(3.5-14.9)$ & $<0.001$ & $8.1(3.8-17.1)$ & $<0.001$ \\
\hline
\end{tabular}

${ }^{*} X^{2}$ test.

Chennai, New Delhi and Karachi, respectively. When we assumed everyone with a CMD would need treatment (both undetected and self-reported), the estimated total city-level costs would be Int $\$ 0.5$ billion, Int $\$ 4.1$ billion and Int\$2 billion, respectively for Chennai, New Delhi and Karachi (see online supplemental tables S3 and S4).

\section{DISCUSSION}

We calculated total costs of illness (direct and indirect) and economic burdens of HTN, CHD, ST, DM and its complications, and CKD based on participant reports from a large survey of three major cities of South Asia. Total annual mean economic costs for all CMDs in these 
three metropolitan cities of South Asia was Int $\$ 708$. The total annual costs per patient for individual CMDs and combination of comorbid CMDs varied considerably from Int\$358 (for HTN) to Int $\$ 2342$ (for patients with multiple comorbidities, that is, HTN/DM with at least one complication). Comparing this with gross domestic product (GDP) per capita ${ }^{30}$ for India (Int\$4635.9) and Pakistan (Int\$4309.8), our data show that the presence of multiple comorbid CMDs can account for up to $40 \%$ of per capita expenditures. ${ }^{31}$

We found New Delhi had the highest total cost of treatment among the three cities. This may be because New Delhi has a larger population, ${ }^{28} 29$ a larger percentage of participants in highest wealth index (New Delhi: 68\%, Chennai: 26\%, Karachi: 48\%), and a large percentage of patients being treated in private for-profit settings compared with Chennai and Karachi. Of note, our approach used participants' reported expenditures and these would be low or even nearly free for publicly funded facilities. As a result, average and total costs in Chennai were lower likely due to a higher percentage of patients using government health facilities compared with the other two cities. It is also possible that the costs in for-profit facilities vary and are highest in New Delhi compared with the other cities. ${ }^{30}$

Though total expenditure was highest among the wealthiest group, the largest burden of OOP expenditures was observed in the least wealthy group. Previously published reports from India have also reported high OOP expenditures in low socioeconomic groups. ${ }^{32-34}$ This can lead to catastrophic payments and impoverishment of households. ${ }^{32} 35$ Given limited government financing ( $<2 \%$ of GDP) in both countries, private health facilities cater for the majority of health service use, both OP $(71.7 \%)$ and IP care $(60.1 \%)$, and household savings tend to be the most common financing source $52.5 \%$ of $\mathrm{OP}$ and $47.3 \%$ of IP). This heavy reliance on OOP expenditures (nearly $80 \%$ ) is not surprising and mirrors findings from other studies from India and other World Bank defined LMICs. ${ }^{85-37}$ For example, previous work from India, ${ }^{38}$ Pakistan $^{39}$ and other ${ }^{23}$ LMICs shows that health insurance coverage dismally low for both OP $(3.3 \%)$ and IP care (14.2\%). To address low insurance coverage and high OOP expenditure, in the 2018-2019 union budget, the government of India has announced the Ayushman Bharat Programme to try to increase the accessibility, availability and affordability of all level of health services in India. ${ }^{40}$ Evaluation of the impact of these financing and policy decisions will be helpful in guiding the future modification or continuation of these programmes.

We found that medication accounts for the highest proportion of direct expenditures, followed by investigations and consultation fees. This is similar to previous findings from India that analysed the National Sample Survey Office data. ${ }^{8}$ This is also true for most other low-income countries as found in a previous review from $2013 .{ }^{12}$ Since medications accounted for the highest proportions of OOP expenditures, discount pharmacies and prescription of generic medicines may be options to reduce financial burdens on patients. The government of India has already initiated 'Pradhan Mantri Bhartiya Janaushadhi Pariyojana ${ }^{41}$ and launched discounted pharmacies, that is, Jan Ausahadhi Store (JAS) ${ }^{42}$ to increase the availability of generic medicines. A cost analysis of JAS has shown that most of the costs of medicines at JAS are lower than branded ones. ${ }^{43}$

Overall, the prevalence of DF was $36.1 \%$ in our study. A community-based study conducted in India also reports $40 \% \mathrm{DF}$ in urban areas for IP care. ${ }^{44}$ Women, those that are unemployed, and those without insurance were more likely to experience DF. Wealth was not associated with DF. In another study conducted in four LMICs including India, DF was $65 \%$ for India which is markedly higher than our study as that study was focused on recently hospitalised patients, though in that study, DF was also more common among female and unemployed participants, and participants without insurance. ${ }^{23}$ Insurance appears to be a strong predictor of avoiding DF; as such, universal health coverage may be an important avenue to potentially decrease the financial risks associated with CMDs. In addition, the availability of government health facilities may also lower total OOP expenditures, as was observed in comparing costs in Chennai and the other cities.

CMDs require regular follow-up visits to health facilities leading to loss of working time both for the patient and caregivers; these non-medical and indirect costs contributed to $14 \%$ of the total economic cost in our study. Other studies from India and Pakistan suggest indirect costs for patients with DM and their caregivers were $28.76 \%$ and $15 \%$, respectively. ${ }^{39}{ }^{45}$ Due to differences in methods (minimum wage vs actual individual income), our estimates for indirect costs were likely conservative. In addition to health expenditures, the economies and societies in India and Pakistan also suffer from lost productivity due to deaths from HD, ST and DM amounting to $\$ 53$ billion and $\$ 3.5$ billion, respectively over the period 2005-2015. ${ }^{46}$ These should also be factored into policy decisions regarding action to address CMDs going forward.

Twenty-two per cent of total participants with selfreported CMDs did not report receiving any treatment. Though they were not enumerated in this study, in the absence of treatment, these individuals may experience acute complications, which are hugely expensive resulting in higher financial burdens and sufferings. Therefore, awareness regarding regular treatment in CMDs and more effective preventive and screening strategies are required to prevent long-term disability. ${ }^{8}$

The high prevalence and economic cost of CMDs in India and Pakistan underline the importance of policy and governance to help steer current health system regulations toward more efficient use of healthcare and better health outcomes. To address acute and chronic disease needs, there is a need to develop a system that provides high-quality, accessible and affordable services. ${ }^{47}$ 


\section{Strengths and limitations}

To the best of our knowledge, this was the first large community-based study from South Asia with primary data collected for cost-of-illness estimation for CMDs. These data were representative of their respective cities. We used age-standardised prevalence, standardised to the world's population in 2010 for calculation of economic burdens to cities. Epidemiological (prevalence of CMDs) and economic survey (direct medical and non-medical cost, indirect cost and source of financing) data were collected from the same population which is an ideal approach to calculate cost of illness and loss of productivity for a city. ${ }^{9}$

Nevertheless, our study had some limitations. The health service utilisation and expenditure data were self-reported and are likely subject to reporting biases. However, for community-level cost data collection, selfreport is the most common method used. Utilisation and cost of treatment were collected for the last 1 year, therefore it is subjected to recall bias. That said, it is unclear which direction the recall bias would influence our estimates-that is, were they higher or lower than in reality? We expect that standardised training and protocols and stringent monitoring of surveys would have minimised these biases. For indirect cost calculations, due to unavailability of data on attendant costs for OP visits, the actual income of the participant, an actual number of days lost for OP care and value of premature mortality caused by CMDs, we expect tour indirect cost estimates are extremely conservative. However, as indirect cost contributes less than $15 \%$ of total economic costs, we would not expect huge variation in total economic costs. For the cost estimates for the undiagnosed, we cannot be sure of this and would propose that the costs of people with undiagnosed DM lie somewhere between 0.5 and 1.5 times what they are for the diagnosed. Therefore, we took the midpoint of 1.0 times (or a 1:1 conversion). Due to the unavailability of recent census data from Pakistan, we used data from 1998 to calculate the population at risk, which can lead to underestimation of total economic burdens for Karachi. All calculated costs do not consider subsidised health services and data to incorporate this component are not available.

\section{CONCLUSIONS}

CMDs constitute a huge economic burden in South Asia. Our analysis took the users' perspective on expenditures and used a cost-of-illness approach. This study highlights the direct, indirect and OOP expenditure CMDs in three major cities of India and Pakistan. Importantly, $80 \%$ of direct expenditures were OOP and $36 \%$ reported requiring DF. These findings highlight major gaps in insurance coverage, health financing, and limited availability and utilisation of public health facilities.

\section{Author affiliations}

${ }^{1}$ Centre for Chronic Disease Control, New Delhi, India
${ }^{2}$ The Centre for Chronic Conditions and Injuries (CCCI), Public Health Foundation of India, New Delhi, India

${ }^{3}$ Madras Diabetes Research Foundation, Chennai, India

${ }^{4}$ Community Health Sciences, Aga Khan University, Karachi, Pakistan

${ }^{5}$ Department of Endocrinology, Metabolism \& Diabetes, All India Institute of Medical Sciences, New Delhi, India

${ }^{6}$ Global Health, Emory University School of Public Health, Atlanta, Georgia, USA ${ }^{7}$ Hubert Department of Global Health, Emory University, Atlanta, Georgia, USA

Acknowledgements The authors would like to thank all participants that gave up their time to participate in this study and provided valuable insights.

Contributors DP, KMN, NT, MMK, VM, AV and MKA conceptualised the survey design and survey methodology. All authors provided intellectual input into the methodology used for this paper. KalpanaS and PG cleaned and analysed the data. KavitaS helped in the interpretation of data. MKA, RS and PG drafted the manuscript. All authors contributed to, reviewed and approved the manuscript.

Funding This study was funded in whole or in part by the National Heart, Lung and Blood Institute, National Institutes of Health ( $\mathrm{NIH})$, Department of Health and Human Services, under Contract No.HHSN268200900026C, and the United Health Group, Minneapolis, Minnesota, USA.

Competing interests None declared.

Patient consent for publication Not required.

Ethics approval The study received approval for human subject's research from the ethics committees of the Public Health Foundation of India and AllMS (both Delhi), Madras Diabetes Research Foundation (Chennai), Aga Khan University (Karachi) and Emory University (Atlanta)

Provenance and peer review Not commissioned; externally peer reviewed.

Data availability statement All data relevant to the study are included in the article or uploaded as supplemental information. Data will be available on reasonable request.

Open access This is an open access article distributed in accordance with the Creative Commons Attribution Non Commercial (CC BY-NC 4.0) license, which permits others to distribute, remix, adapt, build upon this work non-commercially, and license their derivative works on different terms, provided the original work is properly cited, appropriate credit is given, any changes made indicated, and the use is non-commercial. See: http://creativecommons.org/licenses/by-nc/4.0/.

ORCID iD

Priti Gupta http://orcid.org/0000-0002-3929-235X

\section{REFERENCES}

1 World Health Organization. Global status report on noncommunicable diseases 2014. Geneva: WHO, 2014.

2 Siegel KR, Patel SA, Ali MK. Non-communicable diseases in South Asia: contemporary perspectives. Br Med Bull 2014;111:31-44.

3 Institute for Health Metrics and Evaluation University of Washington and Human Development Network. The global burden of disease: generating evidence, guiding Policy-South Asia regional edition, 2013.

4 Jakovljevic M, Timofeyev Y, Ekkert NV, et al. The impact of health expenditures on public health in BRICS nations. J Sport Health Sci 2019;8:516-9.

5 Rijal A, Adhikari TB, Khan JAM, et al. The economic impact of noncommunicable diseases among households in South Asia and their coping strategy: a systematic review. PLoS One 2018;13:e0205745.

6 AHRQ. The burden of non-communicable diseases in the developing world: a role for social and behavioral research. Available: https:// www.ahrq.gov/professionals/education/curriculum-tools/populationhealth/baldwin.html [Accessed 30 Mar 2019].

7 Vellakkal S. Economic implications of chronic diseases in India. South Asia Netw Chronic Dis 2009.

8 Mahal A, Karan A, Engelgau M. The economic implications of noncommunicable disease for India. health, nutrition and population (HNP) discussion paper, 2010.

9 Gupta I, Kandamuthan S, Upadhyaya D. Economic impact of cardiovascular diseases in India. Delhi: Institute of Economic Growth, 2006.

10 Govender VM, Ghaffar A, Nishtar S. Measuring the economic and social consequences of CVDs and diabetes in India and Pakistan. Biosci Trends 2007;1:121-7. 
11 Jakovljevic M, Jakab M, Gerdtham U, et al. Comparative financing analysis and political economy of noncommunicable diseases. J Med Econ 2019;22:722-7.

12 Kankeu HT, Saksena P, Xu K, et al. The financial burden from noncommunicable diseases in low- and middle-income countries: a literature review. Health Res Policy Syst 2013;11:31.

13 Nair M, Ali MK, Ajay VS, et al. CARRS surveillance study: design and methods to assess burdens from multiple perspectives. BMC Public Health 2012;12:701.

14 Ali MK, Bhaskarapillai B, Shivashankar R, et al. Socioeconomic status and cardiovascular risk in urban South Asia: the CARRS study. Eur J Prev Cardiol 2016;23:408-19.

15 International Union For Health Promotion and Education (IUHPE). Macroeconomic impacts of cardiovascular disease prevention in developing countries - IUHPE. Available: http://www.iuhpe.org/index. php/en/non-communicable-diseases-ncds/macroeconomic-impactsof-cardiovascular-disease-prevention-in-developing-countries [Accessed 3 May 2018].

16 Cost of illness studies-A primer. RTI-UNC center of excellence in health promotion economics, 2006.

17 Montvale N. The red book. Medical Economics Company, Inc, 2001.

18 OECD. Demography - Working age population - OECD Data, 2017.

19 Ministry of Labour \& Emplyoment. Government of India. VDA minimum wages order dates 3/4/2018. chief labour commissioner (central). Available: https://clc.gov.in/clc/node/572 [Accessed 6 Aug 2018].

20 Paycheck. Revised Delhi minimum wage April 2018. Available: https://paycheck.in/salary/minimumwages/delhi [Accessed 6 Aug 2018].

21 Paycheck. Minimum wage in Pakistan. Available: https://paycheck. $\mathrm{pk} / \mathrm{salary} / \mathrm{minimum}$-wages/ [Accessed 6 Aug 2018].

22 Xu K. Financing WHOD of HS, allocation E and R. distribution of health payments and catastrophic expenditures methodology, 2005.

23 Huffman MD, Rao KD, Pichon-Riviere A, et al. A cross-sectional study of the microeconomic impact of cardiovascular disease hospitalization in four low- and middle-income countries. PLoS One 2011;6:e20821.

24 World DataBank. PPP conversion factor, GDP (LCU per international $\$)$. world development indicators, 2018.

25 Inflation calculator. Available: http://fxtop.com/en/inflation-calculator php [Accessed 6 Aug 2018].

26 World bank. PPP conversion factor, GDP (LCU per international \$) data. Available: https://data.worldbank.org/indicator/PA.NUS.PPP? locations=IN-PK [Accessed 4 Aug 2018].

27 Briggs A, Gray A. The distribution of health care costs and their statistical analysis for economic evaluation. J Health Serv Res Policy 1998;3:233-45

28 Office of the Registrar General \& Census Commissioner I, Ministry of Home Affairs, Government of India. Census of India Website : Office of the Registrar General \& Census Commissioner, India. Age data. Available: http://www.censusindia.gov.in/2011census/Age_level_ data/Age_level_data.html [Accessed 31 Jul 2019]

29 Population Census Organization. Population by age, sex, urban/rura areas, 1998 census. Available: http://www.pbs.gov.pk/sites/default/
files/other/yearbook2011/Population/16-8.pdf [Accessed 31 Jul 2019].

$30 \mathrm{ICICl}$ Lombard. Treatment costs of common diseases in Indian metros. Available: https://www.icicilombard.com/insuranceinformation/health-insurance-info/article/know-the-costs-of-varioustreatments-in-different-indian-cities [Accessed 31 Jul 2019].

31 World DataBank. GDP per capita, PPP (current international \$) world development indicators, 2018

32 Garg CC, Karan AK. Reducing out-of-pocket expenditures to reduce poverty: a disaggregated analysis at rural-urban and state level in India. Health Policy Plan 2009;24:116-28.

33 Shahrawat R, Rao KD. Insured yet vulnerable: out-of-pocket payments and India's poor. Health Policy Plan 2012;27:213-21.

34 Karan A, Engelgau M, Mahal A. The household-level economic burden of heart disease in India. Trop Med Int Health 2014;19:581-91.

35 Catastrophic payments and Impoverishment due to out-of-pocket health spending. Econ Polit Wkly 2015;50:7-8.

36 Dieleman J, Campbell M, Chapin A, et al. Evolution and patterns of global health financing 1995-2014: development assistance for health, and government, prepaid private, and out-of-pocket health spending in 184 countries. Lancet 2017;389:1981-2004.

37 Dieleman JL, Campbell M, Chapin A, et al. Future and potential spending on health 2015-40: development assistance for health, and government, prepaid private, and out-of-pocket health spending in 184 countries. Lancet 2017;389:2005-30.

38 Ramachandran A, Ramachandran S, Snehalatha C, et al. Increasing expenditure on health care incurred by diabetic subjects in a developing country: a study from India. Diabetes Care 2007;30:252-6.

39 Khowaja LA, Khuwaja AK, Cosgrove P. Cost of diabetes care in out-patient clinics of Karachi, Pakistan. BMC Health Serv Res 2007;7:189.

40 Lahariya C. 'Ayushman bharat' program and universal health coverage in India, 2018. Available: https://www.indianpediatrics.net/ june2018/495.pdf [Accessed 31 Jul 2019].

41 Bureau of Pharma PSUs of India (BPPI). Pradhan Mantri Bhartiya Janaushadhi Pariyojana. Available: http://janaushadhi.gov.in/

42 Travasso C. Discount pharmacies in India will reduce financial burden on patients. BMJ 2015;351:h6394.

43 Mukherjee K. A cost analysis of the Jan Aushadhi scheme in India. Int J Health Policy Manag 2017;6:253-6.

44 Joe W. Distressed financing of household out-of-pocket health care payments in India: incidence and correlates. Health Policy Plan 2015;30:728-41.

45 Grover S, Avasthi A, Bhansali A, et al. Cost of ambulatory care of diabetes mellitus: a study from North India. Postgrad Med J 2005;81:391-5.

46 Abegunde D, Stanciole A. An estimation of the economic impact of chronic noncommunicable diseases in selected countries. World Health organization, Department of Chronic Diseases and Health Promotion (CHP), 2006.

47 Patel V, Parikh R, Nandraj S, et al. Assuring health coverage for all in India. Lancet 2015;386:2422-35. 